\title{
Changing echocardiographic features of a hydatid cyst of the heart
}

\author{
WILLY KOSTUCKI, * MARC VAN KUYK, ^ ANTOINE CORNIL† \\ From the ${ }^{\star}$ Department of Cardiology and the IIntensive Care Department, University Hospital Saint-Pierre, \\ Université Libre de Bruxelles, Brussels
}

SUMMARY A 24 year old woman with pulmonary embolism and a past history of echinococcal disease underwent echocardiography which detected two cysts in the right ventricle which became more solid after treatment with mebendazole. The surgical and pathological findings confirmed the presence of the two cysts and the hydatid nature of the lesion.

Echinococcus disease is common in many parts of the world and affects the heart in $0.5-2 \%$ of cases. ${ }^{1}$ Major complications result almost always from rupture of the cysts either in the pericardium or in the heart chambers. Death may occur from anaphylactic shock, cardiac tamponade, acute pulmonary embolism, subacute or chronic pulmonary hypertension, ${ }^{2}$ systemic embolisation especially in the central nervous system, or secondary generalised hydatidosis. To allow preventive surgical treatment to be undertaken the diagnosis must be made before such complications occur. Although there are few reports of the detection of hydatid cyst of the heart by echocardiography, ${ }^{3-5}$ the present case illustrates the value of this procedure in diagnosing hydatid cyst of the heart and describes the changing echocardiographic features of the disease.

\section{Case report}

A 24 year old Moroccan woman was admitted at 36 weeks' of pregnancy because of pulmonary embolism. She had emigrated from Morocco four years before admission. Three years previously she had been admitted to the same hospital, where the diagnosis of pulmonary hydatid disease had been made. She refused surgical treatment and received a course of treatment with mebendazole. Her pregnancy was normal until the thirty sixth week when she was admitted because of the sudden onset of haemo-

Requests for reprints to Dr Willy Kostucki, Department of Cardiology, Hôpital Universitaire Saint-Pierre, Rue Haute 322, B - 1000 Brussels, Belgium. ptysis, cough, dyspnoea, and sharp right chest pain aggravated by deep breathing.

On admission physical examination showed tachypnoea, tachycardia, and peripheral cyanosis. Clinical examination of the heart was normal, as was the electrocardiogram. Chest radiographs showed multiple round pulmonary shadows in the left lower and right upper lobes. Pulmonary embolism was confirmed by ventilation-perfusion radionuclide images but femorocaval phlebography failed to detect thrombosis.

To investigate a possible cardiac cause for pulmonary embolism, echocardiography was performed using a mechanical sector scanner (ATL) with a 3 $\mathrm{MHz}$ transducer. Cross sectional echocardiography detected two echo free areas $(1.0 \mathrm{~cm} \times 1.5 \mathrm{~cm}$ and 0.5 $\mathrm{cm} \times 1.0 \mathrm{~cm}$ ) indicating the presence of cysts in the inferior wall of the right ventricle. The best images were obtained in the apical four chamber and subcostal view (Figure $a$ ).

A six week trial course of -mebendazole $4 \mathrm{~g}$ daily was given and at the end of the medical treatment, a further echocardiogram was recorded (Figure $b$ ). Although the two echocardiographic views are not strictly identical (partly because of right ventricular enlargement secondary to pulmonary hypertension which developed meanwhile) the different appearances indicate a change in the nature of the hydatid cyst. Since hydatid material was probably still present, surgical treatment was undertaken. Two cysts with evidence of partial rupture were excised, and pathological examination confirmed the presence of hydatid material. 

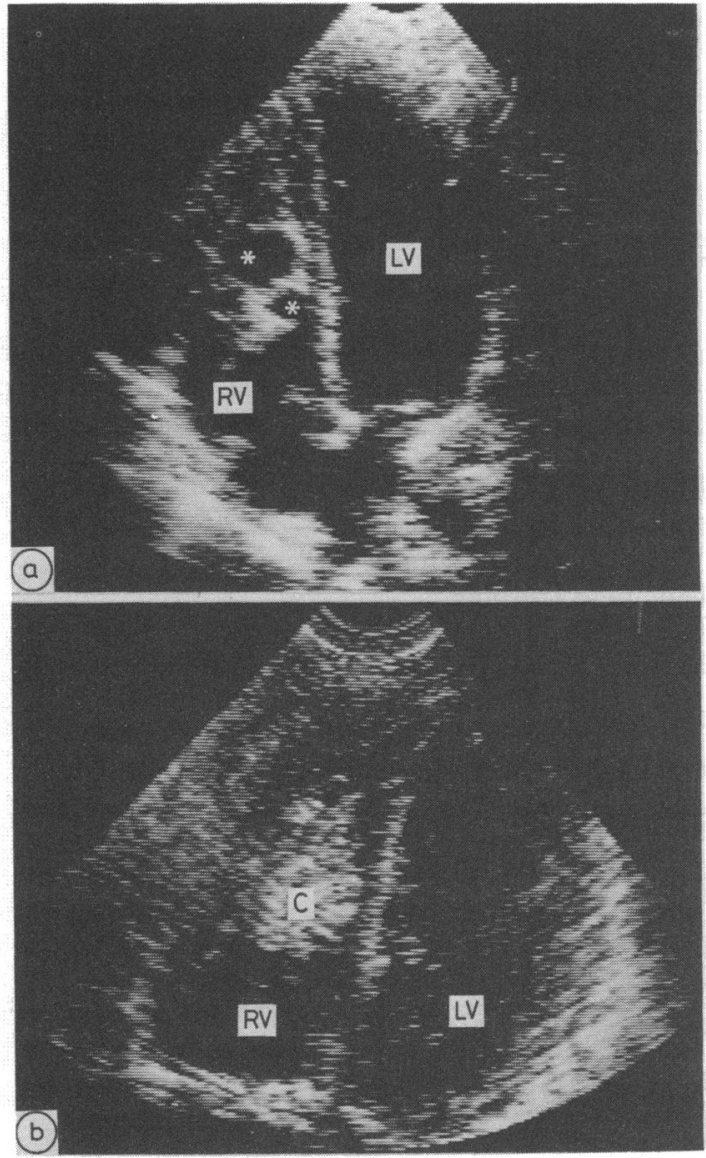

Figure Cross sectional echocardiograms obtained from a slightly modified apical four chamber view showing $(a)$ the bilobulated cyst $\left(^{\star}\right)$ located in the right ventricle $(R V)$ and $(b)$ the cyst (C) filled with echodense material six weeks later. The right ventricle is dilated. $L V$, left ventricle.

\section{Discussion}

This unusual case of pulmonary embolism secondary to a hydatid cyst of the right ventricle illustrates the fact that hydatid cyst of the heart is rarely diagnosed clinically, even in a patient with echinococcal disease, because of the lack of specific clinical and radiological features. If this condition is, however, suspected echocardiography is the method of choice in its diagnosis. This report demonstrated the ability of echocardiography to detect two cysts in the right ventricle. The cross sectional echocardiographic differential diagnosis of a cystic lesion includes hydatid cyst of the heart and the very rare cystic teratoma. ${ }^{6}$ Nevertheless, hydatid cyst of the heart may also resemble a tumour like lesion echocardiographically. The echocardiographic evidence of a cystic hydatid lesion changing into a filled cyst has been reported only in association with hydatid cysts of the lungs and liver, which are probably due to the detachment of the germinative membrane suggesting an involution of the parasite after chemotherapy. ${ }^{7}$

Although this case seems to indicate the effectiveness of high doses of mebendazole in the treatment of hydatid cyst of the heart, we do not believe that this treatment would have prevented further rupture of the cyst and embolisation of the hydatid material, which, even if aseptic, would in this case have increased the pulmonary hypertension. Surgery remains the treatment of choice.

\section{References}

1 Dodek A, de Mots $\mathrm{H} \mathrm{Jr}$, Antonovic JA, Hodham RP. Echinococcus of the heart. An unusual tumor of the heart and liver. Am F Cardiol 1972; 30: 293-7.

2 Perez-Gomez F, Duran H, Tamames S, Perrote JL, Blanes A. Cardiac echinococcosis: clinical picture and complications. Br Heart $\mathcal{f}$ 1973; 35: 1326-31.

3 Limacher MC, McEntee $\mathrm{CW}$, Attar M, et al. Cardiac echinococcal cyst: diagnosis by two dimensional echocardiography. $\mathcal{A}$ Am Coll Cardiol 1983; 2: 574-7.

4 Guillot B, André-Fouet X, Chuzel M, et al. Kyste hydatique du coeur diagnostiqué par échographie bidimensionnelle. Arch Mal Coeur 1982; 75: 1431-5.

5 Ernst A, Cikes I, Radovanovic N. Two-dimensional echocardiographic study of a cardiac hydatid cyst. Am $\mathcal{F}$ Cardiol 1983; 52: 1361-3.

6 McAllister HA Jr. Primary tumors and cysts of the heart and pericardium. Curr Probl Cardiol 1979; 4: 1-31.

7 Bekhti A, Nizet M, Capron M, et al. Chemotherapy of human hydatid disease with mebendazole. Follow-up of 16 cases. Acta Gastroenterol Belg 1980; 43: 48-65. 